\title{
Frequent users of the pediatric emergency department
}

\author{
Jade Seguin, MD*; Esli Osmanlliu, MD; Xun Zhang, $\mathrm{PhD}^{\ddagger}$; Virginie Clavel, MD; Harley Eisman, $\mathrm{MD}^{*}$; \\ Robert Rodrigues*; Maryam Oskoui, MD, $\mathrm{MSc}^{\dagger}$
}

\section{ABSTRACT}

Objectives: Emergency department (ED) crowding is associated with increased morbidity and mortality. Its etiology is multifactorial, and frequent ED use (defined as more or equal to five visits per year) is a major contributor to high patient volumes. Our primary objective is to characterize the frequent user population. Our secondary objective is to examine risk factors for frequent emergency use.

Methods: We conducted a retrospective cohort study of pediatric emergency department (PED) visits at the Montreal Children's Hospital using the Système Informatique Urgence (SIURGE), electronic medical record database. We analysed the relation between patient's characteristics and the number of PED visits over a 1-year period following the index visit.

Results: Patients totalling 52,088 accounted for 94,155 visits. Of those, $2,474(4.7 \%)$ patients had five and more recurrent visits and accounted for $16.6 \%(15,612$ visits $)$ of the total PED visits. Lower level of acuity at index visit (odds ratio [OR] 0.85) was associated with a lower number of recurrent visits. Lower socioeconomic status (social deprivation index OR 1.09, material deprivation index OR 1.08) was associated with a higher number of recurrent visits. Asthma (OR 1.57); infectious ear, nose, and sinus disorders (OR 1.33); and other respiratory disorders (OR 1.56) were independently associated with a higher incidence of a recurrent visit within the year following the first visit.

Conclusion: Our study is the first Canadian study to assess risk factors of frequent pediatric emergency use. The identified risk factors and diagnoses highlight the need for future evidence-based, targeted innovative research evaluating strategies to minimize ED crowding, to improve health outcomes and to improve patient satisfaction.

\section{RÉSUMÉ}

Objectifs: L'encombrement des services des urgences est associé à une augmentation de la morbidité et de la mortalité. Les causes sont nombreuses, et l'utilisation fréquente des services des urgences (définie comme 5 consultations ou plus par année) est un facteur important du nombre élevé de patients. L'étude avait donc pour objectif principal de caractériser la population d'utilisateurs fréquents; et pour objectif secondaire, d'examiner les facteurs de risque d'utilisation fréquente des services des urgences.

Méthode: II s'agit d'une étude de cohorte, rétrospective, portant sur les consultations au service des urgences pédiatriques (SUP) de I'Hôpital de Montréal pour enfants, et menée à l'aide de la base de données Système Informatique Urgence (SIURGE) de dossiers médicaux électroniques. Nous avons analysé la relation entre les caractéristiques des patients et le nombre de consultations au SUP, sur une période d'un an à partir de la consultation de référence.

Résultats: Nous avons dénombré 94155 consultations pour 52088 patients. Parmi ces derniers, $2474(4,7 \%)$ ont consulté cinq fois ou plus, ce qui représente 16,6 \% (15612 consultations) du nombre total de consultations au SUP. Un faible degré de gravité au moment de la consultation de référence (risque relatif approché $[R R A]: 0,85)$ a été associé à un nombre moindre de nouvelles consultations. Par contre, une classe socioéconomique inférieure (indice de défavorisation sociale : $\operatorname{RRA}=1,09$; indice de défavorisation matérielle : $R R A=1,08)$ a été associée à un nombre élevé de nouvelles consultations. Enfin, l'asthme (RRA $=1,57$ ), les infections du nez, des oreilles et des sinus ( $R R A=1,33$ ) ainsi que d'autres troubles respiratoires ( $R R A=1,56)$ se sont révélés des facteurs indépendants d'une incidence élevée de nouvelles consultations au SUP au cours de l'année suivant la consultation de référence.

Conclusions: II s'agit là de la première étude menée au Canada, visant à évaluer les facteurs de risque d'utilisation fréquente des SUP. Les facteurs de risque et les diagnostics dégagés font ressortir la nécessité de mener des recherches innovantes, ciblées et fondées sur des données probantes, qui visent à évaluer différentes stratégies afin de réduire I'encombrement des SU, d'améliorer les résultats cliniques et d'accroître le degré de satisfaction des patients.

Keywords: crowding, emergency services, frequent users, pediatric emergency department

From the *Division of Emergency Medicine and tDivision of Pediatric Neurology, Department of Pediatrics, Montreal Children's Hospital, McGill University Health Centre, Montreal, QC; and the $¥$ Centre for Outcome Research and Evaluation, Research Institute, McGill University Health Centre, Montreal, QC.

Correspondence to: Dr. Jade Seguin, Department of Pediatrics, Division of Emergency Medicine, Montreal Children's Hospital, McGill University Health Centre, 1001 Boulevard Décarie, Montréal, OC H4A 3J1; Email: jade.seguin@mail.mcgill.ca

(C) Canadian Association of Emergency Physicians

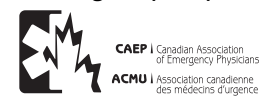

CJEM 2018;20(3):401-408

CJEM $\cdot J C M U$
DOI 10.1017/cem.2017.15 


\section{INTRODUCTION}

In the past decade, emergency department (ED) visits for children have increased to more than 25 million annually in the United States. ${ }^{1}$ According to the Canadian Institute for Health Information, children less than 5 years old constituted the most frequent visitors of Canadian EDs, with $8.7 \%$ of total $\mathrm{ED}$ visits. The number of visits at a Canadian pediatric hospital ED between 2002 and 2011 increased by $30 \%{ }^{2}$

The increased use of ED services is recognized as a contributor to crowding. Other factors include delays in patient transfer from the ED, limited primary care access, and ED staff training limitations. ${ }^{2}$ ED crowding can be defined as a situation where the need for emergency services exceeds the available resources for patient care ${ }^{3}$ and can lead to compromised quality and access to health care. ${ }^{4}$ Improvement in adult ED crowding has been associated with decreased mortality rate among admitted patients, ${ }^{5}$ and ED crowding has been associated with increased costs, adverse outcomes, and overflow in hospital.

The etiology of pediatric emergency department (PED) crowding is multifactorial, attributing to input, throughput, and output factors of the PED. Whereas the delay of admitted patient transfer is recognized as the leading determinant of adult ED crowding, patient volume represents a stronger contributor of PED crowding. Frequent ED use and non-urgent visits are thought to significantly contribute to the high volumes of patients seen in PED. ${ }^{4}$ Pediatric studies reveal that up to $72 \%$ of PED visits were accounted for by frequent users. $^{5-8}$

Children who frequently use the ED have notably had a poorer quality of life and more school absenteeism. ${ }^{6,9,10}$ Improvement in adult ED crowding has been associated with decreased mortality rate among admitted patients. ${ }^{5}$ Factors that can lead to ED crowding, such as frequent $\mathrm{ED}$ use, merit more attention in pediatric emergency medicine research. Further studies exploring the organization, delivery of services, and cost-effectiveness are needed to improve pediatric emergency evidence-based practice.

Frequent ED use is defined as recurrent ED use over a period of time by certain individuals. ${ }^{11,12}$ The cut-off number of $\mathrm{ED}$ visits required to be classified as a frequent ED user varies from 2-12 times per year. ${ }^{13-16}$ The most widely used definition of frequent $\mathrm{ED}$ users includes patients who present repeatedly due to non-random events of five or more times per year. ${ }^{17}$

The U.S. literature reveals that patients of younger age, of black, Hispanic, or Native American ethnicity and covered by public insurance and known for chronic conditions are more likely to have recurrent ED visits. ${ }^{18}$ This literature may not be applicable in Canada where the PED population seems to be healthier, as shown by a recent publication ${ }^{19}$ that revealed that in 2012-2013, $83 \%$ of PED visits were for ambulatory care.

A better assessment of frequent ED user characteristics is essential to offer evidence-based primary care interventions tailored for these patient populations. From the current pediatric literature, little is known about the demographics, diagnoses, and acuity level of the patients who frequently use the PED in Canada.

\section{STUDY OBJECTIVES AND HYPOTHESIS}

Our primary objective is to characterize the frequent PED user population. Our secondary objective is to examine risk factors for frequent PED use.

We hypothesize that children younger than 1 year of age, of low socioeconomic status, and with higher acuity at first presentation are more likely to frequently use the PED.

\section{METHODS}

\section{Study design and setting}

We conducted a retrospective cohort study of PED visits at a single tertiary care hospital. The institutional research ethics board approved the study.

We included all patients ages $0-18$ years who presented to the ED of the Montreal Children Hospital from January 1, 2013 to December 31, 2014. Following the index visit in 2013, we recorded return visits during the following 365 days. We excluded patients who died within the study period. The term frequent user was defined as a patient with five or more visits to the PED within 1 year following the index visit.

Data were abstracted from the SIURGE electronic database (Logibec Groupe Informatique Inc., Montréal), the ED patient tracking database of the Montreal Children's Hospital. Data were collected and entered in the SIURGE database on a daily basis by the treating emergency physicians, residents, nurses, and administrative clerks. The SIURGE database is a 
Montreal Children's Hospital internal computerized patient tracking system, which features a triage module based on the Canadian Triage and Acuity Scale (CTAS) categories. It has been in use in our institution since 2000. Pre-set data were collected on the individual patients. Patients were given International Classification of Diseases (ICD)-10 diagnoses based on the physician's understanding of the illness at the time of discharge or transfer from the unit.

\section{Demographic and clinical variables}

Variables recorded in the SIURGE database were included and data were extracted. Recorded demographic characteristics include age, sex, and a six-digit postal code. Clinical characteristics include level of acuity, length of stay, and the diagnoses at each ED visit. Level of acuity is assessed based on the CTAS. There are five CTAS levels designed, such that level 1 represents the critically ill patient requiring immediate medical attention, and level 5 represents the least ill patient.

The primary diagnoses are classified according to the ICD-10, then further grouped into the ten most frequent diagnosis grouping system subgroups based on data previously published by PECARN in $2014^{7}$ as described in the paragraph on diagnosis grouping system subgroups.

The area level socioeconomic status is obtained using the material and social deprivation index developed by Pampalon and Raymond in 2000, ${ }^{20-22}$ derived from sixdigit postal codes. The deprivation index is based on the dissemination areas (DAs), which are the smallest available geographic units from the national census for which data are available from Statistics Canada, with a population varying between 400 and 700 people. These DAs are considered relatively homogeneous in socioeconomic composition and are linked to the six-digit postal codes available in the REPACQ registry (Registre de la Paralysie Cérébrale au Quebec) using the postal code conversion file from Statistics Canada. The deprivation index is derived from six indicators, three for material and three for social components. The material component is composed of the 1) proportion of the population ages 15 years and over without a high school diploma or equivalent, 2) employmentto-population ratio for the population, and 3) average income of the population ages 15 years and over. The social component is composed of the 1) proportion of individuals ages 15 years and older living alone, 2) proportion of the population ages 15 years and over who are separated, divorced, or widowed, and 3) proportion of single-parent families. Five of these six indicators are adjusted for age and sex, except for the proportion of single-parent family indicator. The deprivation indices provide deprivation scores for each DA. These scores are divided into quintiles, with Quintile 1 representing the most privileged group and Quintile 5 representing the most disadvantaged group. This deprivation index is used as the final area-level measure of socioeconomic status.

\section{Diagnosis grouping system subgroups}

In the SIURGE database, the primary diagnosis is entered based on ICD-10 coding. ICD-10 coding now includes a total of 71,924 codes for procedures and 69,823 codes for diagnoses. We based the classification on the top 10 most frequent diagnosis grouping system subgroups published by the PECARN group in $2014 .^{7}$ The 10 subgroups include asthma, infectious ear/nose/ sinus disorders (including upper respiratory infection), fever, viral illnesses, other respiratory diseases, other gastrointestinal diseases, infectious respiratory diseases, noninfectious skin/dermatologic/soft-tissue diseases, gastroenteritis, and non-infectious neurological disorders.

The number of visits for each patient is calculated to classify frequent users. Demographic and clinical characteristics at baseline are summarized by proportions for categorical data and by median (interquartile range) for continuous data, stratified by frequent users versus non-frequent users. A logistic regression is used to assess the impact of the baseline demographic and clinical characteristics (determined as a priori, as described in the section on demographic and clinical variables), and the Quebec deprivation index on the frequent users. A negative binomial model is also used to assess the impact of these variables on the recurrent visit. All data analyses were carried out using SAS version 9.4 (SAS Institute, Cary, NC).

\section{RESULTS}

During the study period, a total of 52,088 patients accounted for 94,155 visits. In this cohort of 52,088 patients, patients had between 0 and 24 ED visits within a year: $58.4 \%$ of patients had no recurrent visits, $22.7 \%$ had one, $9.8 \%$ had three, $4.4 \%$ had four, and $4.7 \%$ had 
five or more recurrent visits. Those 2,474 (4.7\%) patients with five and more recurrent visits accounted for $16.6 \%$ (15,612 visits) of the total PED visits. The demographic and clinical characteristics of this cohort are shown in Table 1.

The distribution of primary diagnosis at each visit is outlined in Table 2. Overall, ear, nose, and sinus disorders were the most common subgroup across all numbers of recurrent visits. Infectious respiratory diseases, asthma, and non-infectious neurological disorders accounted for other frequent diagnosis subgroups in frequent ED users.

\section{Predictors of frequent ED use}

The association between demographic and clinical variables and the number of recurrent visits is depicted

\begin{tabular}{|c|c|c|}
\hline & $\begin{array}{l}\text { ER visits } \leq 4 \\
(n=49,614)\end{array}$ & $\begin{array}{c}\text { ER visits } \geq 5 \\
(n=2,474)\end{array}$ \\
\hline Sex (male) \% & 54 & 55.8 \\
\hline Age median $(I Q R)^{*}$ & $5(1-10)$ & $1(0-5)$ \\
\hline \multicolumn{3}{|l|}{ Quebec deprivation index } \\
\hline Social median $(I Q R)^{*}$ & $3(2-4)$ & $4(2-5)$ \\
\hline Material median $(I Q R)^{*}$ & $3(1-4)$ & $3(2-5)$ \\
\hline Hours of stay median $(I Q R)^{*}$ & $3.3(2.1-5.1)$ & $3.2(2.0-4.9)$ \\
\hline $\begin{array}{l}\text { Canadian Triage and Acuity Scale } \\
\text { median }(I Q R)^{*}\end{array}$ & $4(3-5)$ & $4(3-4)$ \\
\hline
\end{tabular}

in Figures 1 and 2. Figure 1 demonstrates that younger age is associated with increased recurrent visits. The number of visits decreases significantly by school age. Figure 2-A depicts the association between higher level of acuity at initial presentation and increased ED recurrent visits. Figure 1-B and 1-C outlines the association between a lower socioeconomic status (higher material and social deprivation index) and higher number of recurrent visits.

A logistic regression model was performed to assess independent predictors of frequent ED use (Table 3). Lower age, higher Quebec deprivation index (social and material), and a lower triage and acuity scale at the

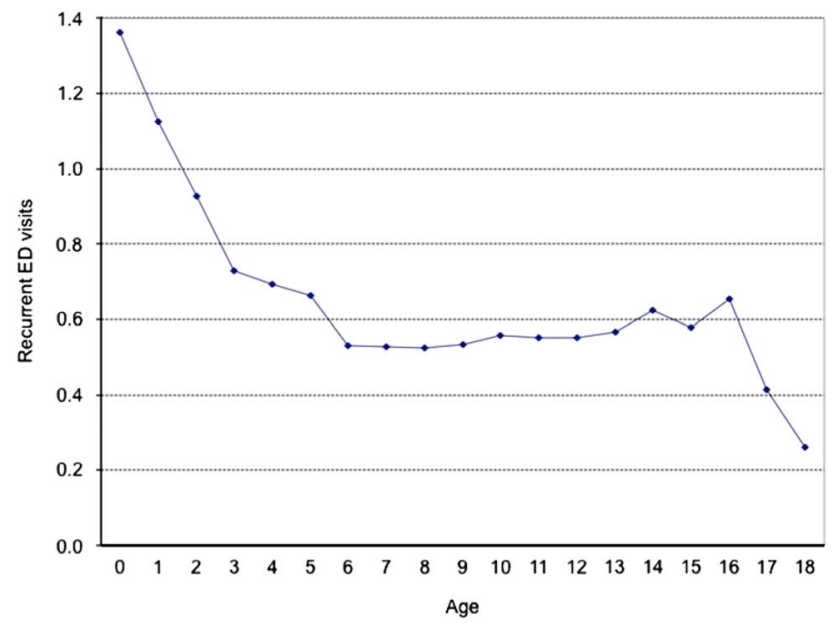

Figure 1. Recurrent emergency visits according to age. The $Y$ axis is the mean number of recurrent emergency department visits.

\begin{tabular}{|c|c|c|c|c|c|}
\hline \multirow[b]{2}{*}{ Diagnosis } & \multicolumn{5}{|c|}{ Order of visit } \\
\hline & $\begin{array}{c}1 \\
(n=52,088)\end{array}$ & $\begin{array}{c}2 \\
(n=21,694)\end{array}$ & $\begin{aligned} & 3 \\
&(n=9,875)\end{aligned}$ & $\begin{aligned} & 4 \\
&(n=4,782)\end{aligned}$ & $\begin{array}{c}\geq 5 \\
(n=2,474)\end{array}$ \\
\hline Asthma* & 2.9 & 4.1 & 4.9 & 6.4 & 7.3 \\
\hline Infectious ear, nose, and sinus disorder* & 15.6 & 17.3 & 19.3 & 21.1 & 20.8 \\
\hline Fever & 2.4 & 2.8 & 2.8 & 3.0 & 2.9 \\
\hline Viral illness & 0.1 & 0.1 & 0.2 & 0.2 & 0.4 \\
\hline Other respiratory diseases & 0.3 & 0.3 & 0.6 & 0.6 & 0.4 \\
\hline Other gastrointestinal disorders & 6.6 & 5.8 & 5.6 & 5.5 & 5.0 \\
\hline Infectious respiratory diseases* & 6.4 & 8.3 & 9.7 & 12.1 & 12.8 \\
\hline $\begin{array}{l}\text { Noninfectious skin, dermatologic, and soft tissue } \\
\text { disease }\end{array}$ & 1.6 & 2.0 & 2.0 & 1.9 & 1.6 \\
\hline Gastroenteritis & 3.8 & 4.3 & 4.0 & 4.0 & 3.6 \\
\hline Non-infectious neurological disorders & 10.5 & 8.6 & 7.7 & 7.2 & 6.8 \\
\hline
\end{tabular}



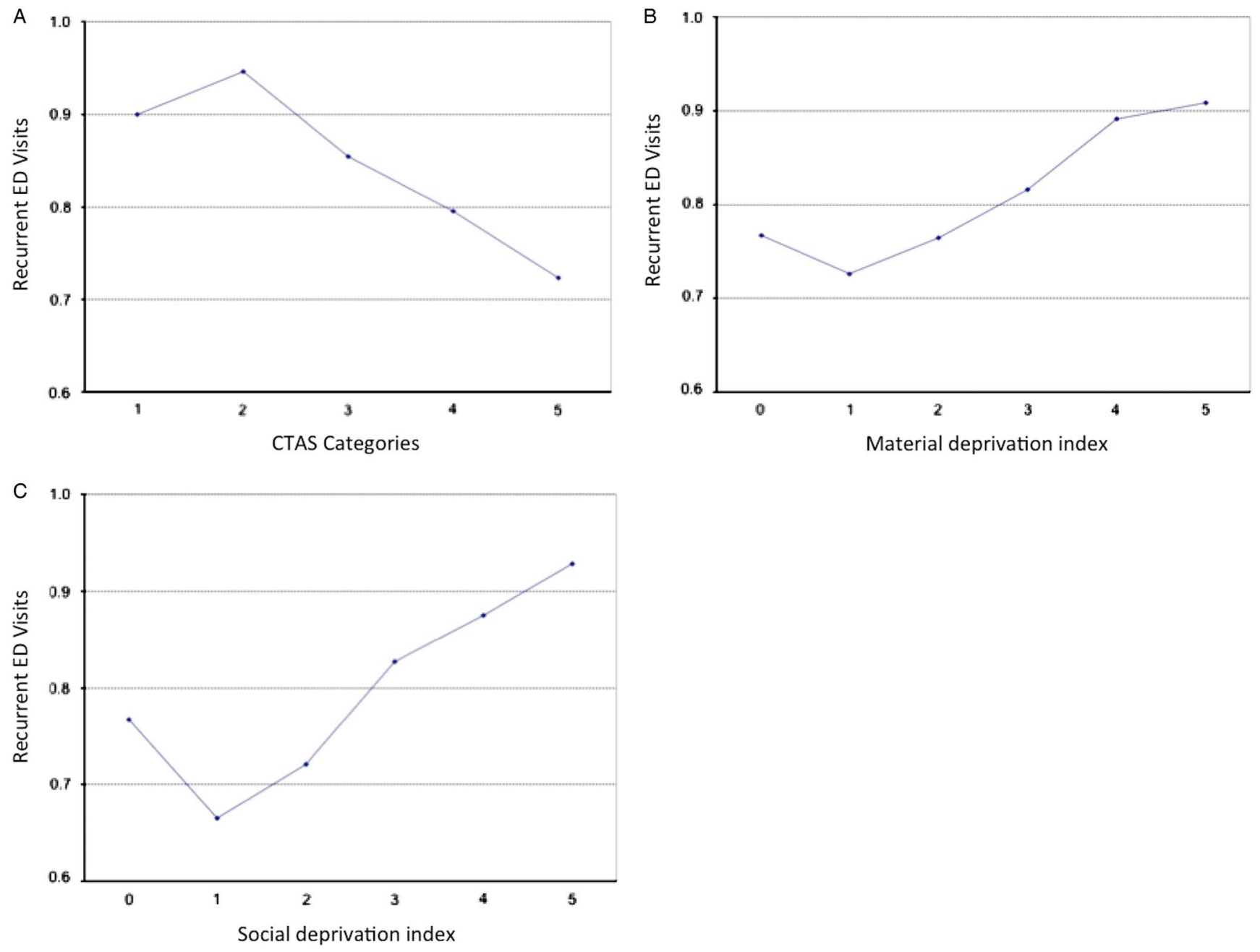

Figure 2. Recurrent emergency visits according to the A) Canadian Triage and Acuity Scale (1-5), B) material deprivation index $(0-5)$, and $C$ ) social deprivation index $(0-5)$. The $Y$ axis is the mean number of recurrent emergency department visits.

\begin{tabular}{|c|c|c|}
\hline & Odds ratio & $95 \% \mathrm{Cl}$ \\
\hline Sex (female v. male) & 0.97 & $0.89-1.06$ \\
\hline Older age & 0.89 & $0.89-0.90$ \\
\hline \multicolumn{3}{|l|}{ Quebec deprivation index } \\
\hline Social & 1.09 & $1.06-1.12$ \\
\hline Material & 1.08 & $1.05-1.11$ \\
\hline Low Canadian Triage and Acuity Scale at index visit & 0.85 & $0.82-0.89$ \\
\hline \multicolumn{3}{|l|}{ Primary diagnosis at index visit } \\
\hline Asthma & 1.57 & $1.24-1.99$ \\
\hline Infectious ear, nose, and sinus disorder & 1.33 & $1.20-1.48$ \\
\hline Infectious respiratory diseases & 1.56 & $1.31-1.85$ \\
\hline
\end{tabular}

index visit were all independent predictors of recurrent ED visits. We also identified that the top three index visit diagnoses - asthma, infectious ear/nose/sinus disorders, and other respiratory disorders - were independently associated with a higher incidence of frequent ED visits within the year following the index visit. 
A negative binomial regression model was used to assess the impact of these variables on recurrent ED visits and yielded similar results.

\section{DISCUSSION}

To our knowledge, this is the first Canadian study to look at characteristics of frequent PED users in a tertiary care institution. The large catchment area, the multicultural, and social diversity of our patient population as well as the urban setting of our institution are characteristics shared by many other PEDs across North America, and, although our study was singlecentred, these similitudes render our findings interesting to these institutions. Moreover, ED crowding is being recognized as a global public health problem, affecting patients and hospital staff. ${ }^{23}$ The etiology of this problem is multifactorial and depends largely on health care system characteristics and services in place. Limited access to primary care, lack of continuity of care, and long delays in getting appointments are known risk factors for non-urgent emergency use. ${ }^{8,24,25}$ In the province of Quebec, a study of adult patients revealed that accessibility, perception of need, familiarity, and trust in the department were the main reasons explaining why patients did not seek primary care prior to visiting the ED. In fact, only $20 \%$ of patients had been referred by their physician. ${ }^{26}$ In the literature, the inappropriate use of ED has been shown to account for up to $40 \%$ of PED visits. ${ }^{27}$

On the other hand, our results identify that children with a higher severity score on the index visit are more likely to re-present to the ED. This finding suggests that critically ill patients are more likely to appropriately use the PED more often. ${ }^{7}$ Our study also agrees with earlier findings that young children are more frequent users. This population tends to be more high risk with admission rates in neonates reported as high as $38 \% .{ }^{28}$ Such patient groups require emergent medical attention and appropriately use the ED more often. Indicators such as CTAS score at triage and hospital admissions are helpful in determining the "appropriateness" of an ED visit. The inability to include information on ED discharge disposition in our study population limits our ability to characterize the preventability of certain ED visits. Of note, a Canadian retrospective study on PED use in British Columbia reports that during a period where annual $\mathrm{PED}$ visits increased by $30 \%$, visits triaged CTAS 1 and CTAS 3 remained constant ( $<10 \%$ increase), whereas CTAS 2 doubled, CTAS 4 increased by $30 \%$, and CTAS 5 nearly quadrupled. ${ }^{29}$

We identified that $4.7 \%$ of our population had five or more visits to the PED. This group of patients accounted for $16.6 \%$ of the total ED visits. This number, although significant, is lower than what has been published in the pediatric literature, where up to $72 \%$ of visits were accounted for by frequent users. $^{7,8,30,31} \mathrm{We}$ suspect that the presence of two tertiary care hospitals within the city of Montreal is a major contributor to this low number. Certain diagnoses are associated with an increased emergency service use. We identified that asthma, infectious ear/nose/ sinus disorders, and other respiratory disorders were independently associated with a higher incidence of recurrent visits within the year following the index visit. Non-infectious neurological disorders as well as gastrointestinal disorders other than gastroenteritis, respectively, account for the fourth and fifth most common primary diagnoses and predicted frequent PED use.

Asthmatic children are known to frequently visit the ED for exacerbations. Known contributing factors include poor compliance, insufficient knowledge of medical management, ineffective application of management action plan, and limited access to an asthma care provider. ${ }^{32,33}$ Key interventions, such as preprinted order sheets and access to a pediatrician for consultation, have been shown effective in diminishing utilization of emergency services. ${ }^{34}$ Our data did not reveal an increase use of services for the adolescent population, which has very different needs, including mental health and psychological care. ${ }^{35-37}$

Multiple USA-based studies have shown that children who are publicly insured use the ED more frequently when compared with privately insured patients. ${ }^{7,9,38}$ Despite that Quebec has a public health care system accessible to all, we found that children of lower socioeconomic status are more likely to be frequent ED users. This finding may suggest that other social determinants of health, beyond health insurance status, may lead to increased PED use.

\section{LIMITATIONS}

Our study has several strengths, as well as limitations. The data are entered in the SIURGE database in a prospective and systematic fashion for all patients cared 
for at the PED of the Montreal Children's Hospital. This provides data for a large cohort of patients over time. However, these data are collected by various health care professionals (i.e., staff, fellows, residents, students, clerks), introducing the risk of heterogeneity and report bias. Moreover, we would ideally assess ED reliance, which is the ratio of ED visits to primary care provider visits. Unfortunately, the SIURGE database does not allow us to know whether a given patient has an identified primary care provider or the extent of visits at other health care facilities. Given that within the Montreal area, there are two tertiary pediatric care centres, we may underestimate the number of recurrent visits. We were also unable to assess for comorbidities because this was not recorded in the SIURGE database. Given our sample size and resources, it was not feasible to use alternative data sources such as electronic medical records or patient interviews. Nevertheless, we believe that this large scale characterization of the frequent users is a crucial step that will allow us to narrow future analyses and allow us to characterize further the smaller groups identified.

\section{CONCLUSION}

Evidence-based, innovative strategies are needed to minimize frequent PED use. This, in turn, could lead to improved health outcomes, optimized provision of both urgent and non-urgent care, and less potentially avoidable, high-cost ED encounters. Future studies evaluating interventions tailored for the frequent user population and optimization of outpatient ambulatory care services are needed to develop sustainable solutions.

\section{Competing interests: None declared.}

Financial support: Dr. Maryam Oskoui received an operating grant from the Research Institute of the McGill University Health Centre (no grant number).

\section{REFERENCES}

1. McCaig LF, Nawar EW. National Hospital Ambulatory Medical Care Survey: 2004 emergency department summary. Adv Data Anal Classif 2006;372:1-29.

2. Doan Q, Genuis ED, Yu A. Trends in use in a Canadian pediatric emergency department. CFEM 2014;16(05):405-10.

3. Physicians ACoE. Crowding. Ann Emerg Med 2006;47(6):585.

4. Hoot NR, Aronsky D. Systematic review of emergency department crowding: causes, effects, and solutions. Ann Emerg Med 2008;52(2):126-36.
5. Geelhoed GC, de Klerk NH. Emergency department overcrowding, mortality and the 4-hour rule in Western Australia. Med J Aust 2012;196:122-6.

6. Neuman MI, Alpern ER, Hall M, et al. Characteristics of recurrent utilization in pediatric emergency departments. Pediatrics 2014;134(4):e1025-31.

7. Alpern ER, Clark AE, Alessandrini EA, et al. Recurrent and high-frequency use of the emergency department by pediatric patients. Acad Emerg Med 2014;21(4):365-73.

8. Cabey WV, MacNeill E, White LN, et al. Frequent pediatric emergency department use in infancy and early childhood. Pediatr Emerg Care 2014;30(10):710-7.

9. Boulet LP, Belanger M, Lajoie P. Characteristics of subjects with a high frequency of emergency visits for asthma. Am $\mathcal{Z}$ Emerg Med 1996;14(7):623-8.

10. Ben-Isaac E, Schrager SM, Keefer M, et al. National profile of nonemergent pediatric emergency department visits. Pediatrics 2010;125(3):454-9.

11. Locker TE, Baston S, Mason SM, et al. Defining frequent use of an urban emergency department. Emerg Med 7 2007;24(6):398-401.

12. Hunt KA, Weber EJ, Showstack JA, et al. Characteristics of frequent users of emergency departments. Ann Emerg Med 2006;48(1):1-8.

13. Zuckerman S, Shen YC. Characteristics of occasional and frequent emergency department users: do insurance coverage and access to care matter? Med Care 2004;42(2):176-82.

14. Chan BT, Ovens HJ. Frequent users of emergency departments. Do they also use family physicians' services? Can Fam Physician (Medecin de famille canadien) 2002;48:1654-60.

15. Maugein L, Lambert M, Richer O, et al. [Repeat visits in a pediatric emergency department]. Archives de pediatrie: organe officiel de la Societe francaise de pediatrie 2011;18(2):128-34.

16. Kroner EL, Hoffmann RG, Brousseau DC. Emergency department reliance: a discriminatory measure of frequent emergency department users. Pediatrics 2010;125(1):133-8.

17. Locker TE, Baston S, Mason SM, et al. Defining frequent use of an urban emergency department. Emerg Med 7 2007;24(6):398-401.

18. Alpern ER, Clark AE, Alessandrini EA, et al. Recurrent and high-frequency use of the emergency department by pediatric patients. Acad Emerg Med 2014;21(4):365-73.

19. Salois R. Les urgences au Québec: Évolution de 2003-2004 à 2012-2013. Bibliothèque et Archives nationales du Québec: Quebec City; 2014.

20. Pampalon R, Hamel D, Gamache P, et al. An area-based material and social deprivation index for public health in Quebec and Canada. Can 7 Public Health = Revue canadienne de sante publique 2012;103(8 Suppl 2):S17-22.

21. Pampalon R, Hamel D, Gamache $\mathrm{P}$, et al. A deprivation index for health planning in Canada. Chronic Dis Can 2009;29(4):178-91.

22. Pampalon R, Raymond G. A deprivation index for health and welfare planning in Quebec. Chronic Dis Can 2000;21(3): 104-13.

23. Boyle A, Abel G, Raut P, et al. Comparison of the International Crowding Measure in Emergency Departments (ICMED) and the National Emergency Department Overcrowding Score (NEDOCS) to measure emergency 
department crowding: pilot study. Emerg Med 7 2016;33(5): 307-12.

24. Brousseau DC, Bergholte J, Gorelick MH. The effect of prior interactions with a primary care provider on nonurgent pediatric emergency department use. Arch Pediatr Adolesc Med 2004;158(1):78-82.

25. Christakis DA, Mell L, Koepsell TD, et al. Association of lower continuity of care with greater risk of emergency department use and hospitalization in children. Pediatrics 2001;107(3):524-9.

26. Afilalo J, Marinovich A, Afilalo M, et al. Nonurgent emergency department patient characteristics and barriers to primary care. Acad Emerg Med 2004;11(12):1302-10.

27. Benahmed N, Laokri S, Zhang WH, et al. Determinants of nonurgent use of the emergency department for pediatric patients in 12 hospitals in Belgium. Eur $\mathcal{F}$ Pediatr 2012; 171(12):1829-37.

28. Perry AM, Caviness AC, Allen JY. Characteristics and diagnoses of neonates who revisit a pediatric emergency center. Pediatr Emerg Care 2013;29(1):58-62.

29. Quynh Doan EDG. Alvis Yu. Trends in use in a Canadian Pediatric Emergency Department. Can 7 Emerg Med 2014;16(5):405-10.

30. Baquiran RS, Webber MP, Appel DK. Comparing frequent and average users of elementary school-based health centers in the Bronx, New York City. F Sch Health 2002;72(4):133-7.
31. Calado CS, Pereira AG, Santos VN, et al. What brings newborns to the emergency department?: a 1-year study. Pediatr Emerg Care 2009;25(4):244-8.

32. Bartlett SJ, Lukk P, Butz A, et al. Enhancing medication adherence among inner-city children with asthma: results from pilot studies. 7 Asthma 2002;39(1):47-54.

33. Lawson CC, Carroll K, Gonzalez R, et al. "No other choice": reasons for emergency department utilization among urban adults with acute asthma. Acad Emerg Med 2014;21(1):1-8.

34. Guttmann A, Zagorski B, Austin PC, et al. Effectiveness of emergency department asthma management strategies on return visits in children: a population-based study. Pediatrics 2007;120(6):e1402-10.

35. Brennan JJ, Chan TC, Hsia RY, et al. Emergency department utilization among frequent users with psychiatric visits. Acad Emerg Med 2014;21(9):1015-22.

36. Grupp-Phelan J, Harman JS, Kelleher KJ. Trends in mental health and chronic condition visits by children presenting for care at U.S. emergency departments. Public Health Rep 2007;122(1):55-61.

37. Mapelli E, Doan Q. Trends in emergency department utilization by children with mental health issues. Paediatr Child Health 2014;19(6):e99.

38. Adekoya N. Reasons for visits to emergency departments for Medicaid and State Children's Health Insurance Program patients: United States, 2004. N C Med J 2010;71(2):123-30. 